\title{
Cost of the reproduction cycle cancellation
}

\author{
Olga Panfilova ${ }^{1, *}$, and Vladimir Chernenko ${ }^{1}$ \\ ${ }^{1}$ Dept Corporate Finance and Business Valuation Saint-Petersburg State Economic University, 21, Sadovaya sr., St.-Petersburg, Russia
}

\begin{abstract}
Capital reproduction is the fundamental basis and main reason of investment. The investment process in a real economy is subject to the impact of risks. This article will help identify some of the risks affecting the capital reproduction process. Sources of uncertainty and risk are investigated throughout the article. In this article we define the importance of borrowed funds for the national economy and associated risks. The impact of risks on the investment cycle can include a loss of capital gains as a minimum. The worst result of risk on the investment process is the cancellation of the project. A frozen or otherwise discontinued capital reproduction cycle may lead not only to a loss, but also requires additional costs, which fall directly on the particular national economy. This article classified costs accompanying the cancellation of the capital reproduction process. The consequences of cancelling the capital reproduction cycle for the investment process in a national economy are revealed.
\end{abstract}

\section{Introduction}

A lot of authors, starting with medieval philosophers to present day scientists, have researched the question of capital reproduction.

Capital reproduction is the main reason for investment and its fundamental basis.

One of the existing concepts separates the capital reproduction process into two main parts $[1,2]$.

First we will explore the simple way of capital reproduction.

We can encounter the simple way of capital reproduction through trade deals (buying and selling) and performing portfolio management.

Portfolio management is the art and science of making decisions about investment mix and policy, matching investments to objectives, asset allocation for individuals and institutions, and balancing risk against performance [3]. As part of portfolio management we can buy or sell securities, stocks, other assets, and commodities.

The formula for simple capital reproduction shows us that:

If you have free capital you can buy commodities or securities and sell it to achieve a Return on Investment (ROI) with a capital gain [4].

But you might not be so lucky.

If the return on investment is less than the initial capital outlay we have a loss. However, to reduce our risk of loss we can diversify. Diversification is the process of allocating capital in a way that reduces the exposure to any one particular asset or risk.

A common path towards diversification is to reduce risk or volatility by investing in a variety of assets.

The second way of capital reproduction is the expanded method in the real economy.
The formula for expanded capital reproduction shows how to implement investments in the real economy.

In this case if you have free capital you can buy commodities (tangible assets, labor, or technologies) which are necessary for the production process, to produce new goods, to create commodities, and only after that sell it on the open market.

This process leads us to the main goal of achieving capital gain in the form of profit.

\section{Research methodology (risks identification)}

It should be remembered that to create a real investment project takes time. The time factor increases uncertainty and creates risks. The main causes of uncertainty and the sources of risk are:

The spontaneity of natural phenomena and natural disasters, which could have a serious impact on the capital reproduction cycle and be a source of unexpected costs;

The element of chance which can be determined by different factors such as socio-economic and technological processes, and human relations;

This means that each national economy is unique and can have different outcomes and consequences. Therefore, we find the relative impossibility of foresight for the intended result.

The presence of confrontation and conflicts of interest in the socio-economic sphere could result in wars and ethnic conflicts which can create additional risks during the capital reproduction process;

Moreover, the existence of uncertainty is defined as incomplete information about the object, phenomenon, or process, in relation to decisions we make, along with

\footnotetext{
* Corresponding author: ov27vp8@yandex.ru
} 
the variability and the incompleteness of available information or analysis available to us.

The sources contributing to risk can also be attributed to:

-Limited resources in decision making and implementation;

-Lack of technological understanding

-Limitations of human consciousness, differences in the socio-psychological conditions

-Attitudes, intentions, and behavior stereotypes.

In addition, by launching and implementing the capital reproduction process as investment in the real economy, we are changing the external and internal environment. The environment's response to change is a source of uncertainty and, therefore, risks at the micro level and at the macro level.

It is necessary to understand and identify the main types of risk that have a significant impact on the process of implementing investment projects and capital reproduction, as well as their level of occurrence.

We can identify and classify risks that affect the reproduction process according to their origin.

-External or macro-level risks: Political; Social; Legal (taxation in particular); Ecological; Financial; Resources; Technological; Geographic and climate;

-Internal or micro-level risks: Technical; Technological; Personnel; Management; Forms of financing; Operating activities.

Both identified and unidentified risks by sources of their occurrence exert influence on the result of capital reproduction in the investment process.

Objects of risk influence include: dynamics of capital gain and accumulation; GDP growth; the reproduction cycle duration.

The impact of risks on the investment cycle can include a loss of capital gains as a minimum. The worst result of risk on the investment process is the cancellation of the project. In this case, the feasibility of starting a reproduction cycle or participating in its financing should be assessed in terms of possible capital losses compared with the potential to obtain positive capital gains from the created assets. Moreover, we have to take into account the costs of terminating the reproduction process and who from the entire investment process or particular project participants will pay this cost [5].

Practice shows that in conditions of limited financial capital, the investment process in the national economy can be financed from various sources:

First, sources which were accumulated within the national economy;

Second, borrowed funds in the form of loans from international financial organizations such as: the International Monetary Fund; European Central Bank (and etc);

Third, direct foreign investment.

This situation arose as a result of the parallel existence for two capital reproduction methods, to be precise, simple and extended. In turn, a simple capital reproduction method is based on the formation of capital gains as trading results in the ability for capital to reproduce itself. This is facilitated by global financial centers and financial and commodity exchanges [6].

Redundancy of financial capital in one place creates conditions for its redirection in the form of credit or direct investments in order to preserve it and reproduce the capital in another area. This process is not dependent on nationality. The direction of investment is defined only as the optimal ratio of the assets value which is involved in the reproduction process (labor, means of production and raw materials) and profit. It is promoted by the globalization of capital reproduction and by the technological effect from innovations [7].

\section{Results (costs of the reproduction cycle termination)}

Using borrowed capital we undertake conditional obligations to pay for the use of borrowed funds, and return the entire amount of debt in a timely manner in accordance with the agreement. If we attract a loan we have to remember that the capital reproduction cycle must generate capital gains that are more than the sum of interest to be paid back on the loan.

Otherwise, we will have a loss and be unable to pay back the interest on the loan. And if we are asked to repay the loan or pay interest at the investment stage, when the process has not yet led to a return on capital, this can bring a halt in the investment and reproduction process. In this case we can lose not only unfinished assets, but also all the initial capital. This action can mean default and/or bankruptcy and lead to consequences like investment and capital reproduction cancellation. But, despite the fact that our capital reproduction cycle has been cancelled, we have to pay back the loan and with interest as agreed.

If we are successful we can pay back the loan with interest, take a positive result, or reinvest capital gains into a new production cycle.

With regards to a direct investment, all risks which impact the capital reproduction process during the investment phase and project implementation, as well as the accompanying costs, are covered by investors. Investors need to make an informed decision whether to cancel or continue the process.

Although the interest on a loan will increase the cost of the capital reproduction cycle, it may be necessary if domestic capital is not enough to implement projects and there are not interested parties to make a direct investment.

On the other hand, a lack of domestic capital for production cycle replication leads to the internal investment activity cancellation. It requires decision making and a choice between stopping and continuing the reproduction cycle within the national economy. At the same time, the continuation of a cycle requires an understanding for which resources should be used to continue the cycle, taking into account the risks.

One of the motivations for such a choice is that a frozen or otherwise discontinued reproduction cycle may lead to not only a capital loss, but also require additional 
costs, which falls directly on the particular national economy.

Thus, the cost of reproduction cycle cancellation is a factor that must always be taken into account when making decisions about the continuation or termination of the cycle.

The costs of completing the reproduction cycle have little variability depending on the industry or characteristics of the national economy and can be classified as: financial and non-financial; renewable and non-renewable; cost of borrowed funds including interest and associated commissions, penalties, and service fees.

The financial costs of completing the reproduction cycle represent the most basic and largest costs associated with carrying out activities to end the reproduction process and the disintegration of its components: labor force and means of production. Namely:

Costs for the conservation of buildings and other industrial facilities;

Costs of dismantling, moving, storage, and disposal of equipment and / or unused raw materials or waste; taxes and other fees related to the listed activities;

Social costs associated with the dismissal and retraining of the labor force;

Full repayment to financial institutions for existing loans that were taken to complete the capital reproduction cycle, including interest payments;

Non-financial costs, this is primarily negative PR and decrease in creditor and investor confidence, as well as related changes in ratings that directly affects investment activity.

Despite the fact that non-financial costs at the time of cancelling a reproduction cycle are not financial costs, in the long term they may cause additional costs, such as higher interest rates from future lenders, associated with a deterioration of the political or credit rating.

Renewable costs mean that under certain conditions a part of expenses incurred during the reproduction cycle, and even expenses incurred during a set of measures to end the reproductive cycle, can be reimbursed in future periods.

These costs include:

Costs associated with the conservation of productive assets that can be reimbursed if they are reprofiled and used in another more technological and efficient reproduction cycle.

Social expenditures related to re-training can be partially or fully covered by the results of applying retrained labor as intellectual capital, as well as lowering the value of the freed up labor force as a result of its surplus in the market.

National economies in various ways try to avoid the consequences of the risks associated with the reproduction cycle termination. Some, such as Portugal, refuse external loans and stimulate internal demand through subsidies. This contributes to the accumulation of domestic capital. Others, such as, for example, India, Uganda, Kenya, feel the impact of technological unemployment and experiment with the basic income. Also, in the world approach of Sharing Economy is developing.

\section{Conclusions}

Thus, we can conclude that the costs associated with the cancellation of a capital reproduction cycle can be covered or minimized due to the involvement of resources in a new reproductive cycle of another higher quality.

However, as practice shows, such a successful situation can arise only if the economy develops.

The absence of scientific discussion on this issue is explained by the fact that the area for its study lies between academic disciplines such as political science, economics, and corporate finance.

The cost of investment cycle cancellation is studied by corporate finance.

However, the risks, associated with foreign direct investment in a particular national economy and government borrowing from international financial institutions, are studied more by political scientists and macroeconomists.

At the same time, the impact of risks, including the globalization of capital reproduction and the advance of new technologies have a direct influence on the lots of individual projects. It subsequently forms the aggregate costs for a national economy at the macro level.

\section{References}

[1] K. Marx, Capital (Volume II, 1992).

[2] K. Marx, Capital (Volume I, 1990).

[3] D. Lynn, Managing a Modern Commercial Real Estate Portfolio [Electronic resource]. Available at: https://urbanland.uli.org/developmentbusiness/managing-modern-commercial-realestate-portfolio (Accessed: 27.01.2019).

[4] J.M. Pearce, Return on investment for open source scientific hardware development, Science and Public Policy, 43, 2, 192-195 (2016) DOI: 10.1093/scipol/scv034 (Accessed: 12.02.2019).

[5] D. Harvey, The New Imperialism (Oxford: Oxford University Press, 2003).

[6] J. Toporowski, The End of Finance: Capital Market Inflation (Financial Derivatives and Pension Fund Capitalism, Routledge, 2002).

[7] O. Panfilova, V. Okrepilov, S. Kuzmina, Globulizaition impact on consumptions and distribution in society, MATEC Web of Conferences, International Science Conference SPbWOSCE-2017, Business Technologies for Sustainable Urban Development, 01032 (2018).

[8] G.S. Becker, Human Capital: A Theoretical and Empirical Analysis (N.Y.: Columbia University Press for NBER, 1964).

[9] G. Hodgson, Economic theory and institutions: The Manifesto of modern institutional economic theory (Transl. from English, M.: Business, 48, 2003).

[10] J. Kornai, Resource-Constrained versus DemandConstrained Systems, Econometrica, 47, 4, 801819 (1979). 
[11] L. Abalkin, Economic theory to the concept of a long-term strategy (Problems of modern Russia, M., 39-47, 2011).

[12] E.V. Zhertovskaya, M.V. Yakimenko, Analysis of theoretical approaches to the study of the reproductive process and the proportions of regional reproduction, Journal of Fundamental Research, 10, 1511-1515 (2013).

[13] G. Hodgson, Economic theory and institutions: The Manifesto of modern institutional economic theory (Transl. from English, M.: Business, 48, 2003). 